\title{
Correlation of EGFR \& CK 5/6 Expressions with Histological Grading of Breast Carcinoma
}

\author{
Pawan Trivedi $^{1}$, Vidhi Verma ${ }^{1 *}$, Anshita Arora $^{2}$, Pallavi Dubey ${ }^{2}$
}

${ }^{1}$ Assistant Professor; Department of Pathology, Mayo Institute of Medical Sciences, Barabanki, Uttar Pradesh, India

${ }^{2}$ Senior Resident, Department of Pathology, Mayo Institute of Medical Sciences, Barabanki, Uttar Pradesh, India

DOI: $10.36347 /$ sjams.2020.v08i06.024

| Received: 10.06.2020 | Accepted: 18.06.2020 | Published: 24.06.2020

*Corresponding author: Vidhi Verma

\section{Abstract}

Original Research Article

Breast cancer comprises a group of very diverse diseases, which can be demonstrated at the molecular, histopathological and clinical levels. Aim of the study were to evaluate Cytokeratin 5/6 (CK 5/6) and Epidermal Growth Factor Receptor (EGFR) expression and correlation with the histological grading of breast carcinoma. EGFR and CK 5/6 are easily available and specific IHC substitute for basal markers. Cytokeratin (CK) 5/6 and EGFR markers have been used in a panel format to identify "basal-like" carcinomas. Methods: The study was performed for the expression of CK 5/6 and EGFR by Immunohistochemistry (IHC) in 48 breast carcinoma patients, underwent for radical mastectomy and were correlated with the MBR histopathological tumor grades for any significance. Result: Among 48 breast carcinoma cases, majority were grade II followed by grade III and grade I. However, on statistical analysis of correlation of EGFR and CK5/6 expressions with tumor grades were found to be significant with $P$ value $(=0.032661)$ with grade III tumour. The result calculated by SPSS software. Conclusions: Expressions of basal markers like CK 5/6 \& EGFR were found to be statistically significantly correlated with the histological grading of breast carcinoma with majority cases having grade III tumor.

Keywords: Breast carcinoma, Basal-like, Triple-negative, EGFR, CK 5/6, immunohistochemistry.

Copyright @ 2020: This is an open-access article distributed under the terms of the Creative Commons Attribution license which permits unrestricted use, distribution, and reproduction in any medium for non-commercial use (NonCommercial, or CC-BY-NC) provided the original author and source are credited.

\section{INTRODUCTION}

In the current scenario, breast cancer has become one of the most multifaceted diseases, affecting millions of women every year. Breast cancer is a complex disease consisting of distinct biological subtypes with a diverse history and wide-ranging spectrum of clinical, pathological, molecular features [1]. Presently, as a routine investigation of breast carcinoma, three molecular markers; namely ERestrogen receptor, PR-progesterone receptor, HER2human epidermal growth factor receptor 2 gene, have been proven to provide therapeutic, predictive and prognostic value [2].

Based on gene expression profiles (GEP), five molecular subtypes of breast carcinoma have been identified globally (Table 1) [2, 3]. Out of five, one group classified as triple-negative molecular subtype having ER/PR-, HER2neu- expressions and have poor prognosis and therapy response [2, 4]. Triple-negative breast cancer (TNBC) further classified into two subtypes as basal and non-basal. Basal-type was defined as $\mathrm{CK} 5 / 6$ positive and/or EGFR positive and non-basal type showed no expressions of these two markers [5].

Table-1: Molecular subtypes of breast carcinoma based on gene expression profiling (GEP)

\begin{tabular}{|l|l|l|l|}
\hline Molecular subtype & $\begin{array}{l}\text { ER and PR } \\
\text { expression }\end{array}$ & $\begin{array}{l}\text { Her2-neu } \\
\text { expression }\end{array}$ & $\begin{array}{l}\text { Basal markers } \\
\text { expression }\end{array}$ \\
\hline Luminal A & ER/PR +ve & Her-2 negative & \\
Luminal B & ER/PR +ve & Her-2 positive & \\
Her-2 & ER/PR -ve & Her-2 positive & \\
Triple negative & ER/PR -ve & Her-2 negative & Basal markers +ve \\
Normal breast stromal cells like & ER/PR -ve & Her-2 negative & Basal markers -ve \\
\hline
\end{tabular}


Cytokeratin 5 and 6 are type 2 neutral polypeptides. They are expressed in keratinized and non-keratinized squamous epithelium of salivary glands, prostate, and mammary glands [6, 7]. In human breast, these high molecular weight basal cytokeratins are expressed in the myoepithelial cell layer and in a small amount of luminal epithelial cells of the glands [8]. CK 5/6 expression is used in the differential diagnosis of basal-like breast cancer from triplenegative (TN) breast cancer. Its expression correlates with poor prognosis and high-grade differentiation [9, $10]$.

Epidermal growth factor receptors (EGFR) is a member of the ERBB family of receptors. This family includes four tyrosine kinase receptors: EGFR (HER1/c-erbB1), human epidermal growth factor receptor (HER)2/neu (c-erbB2), HER3 (c-erbB3) and HER4(c-erbB4) [11]. Stimulation of EGFR by endogenous ligands results in activation of intracellular tyrosine kinase consequently leads to the inhibition of apoptosis, activation of cell proliferation and increases the metastatic potential. Based on these properties, EGFR was investigated in many human malignant tumors and it is now regarded as a potential target for cancer therapy. In breast cancer, EGFR expression was found mainly in basal-like carcinoma, but many reports already signalled out positive cases associated with HER2 or luminal types. It was shown that EGFR plays a crucial role not only in the molecular diagnosis of breast cancer, but also induces resistance to chemotherapy and radiation treatment, and therefore, is a marker of poor prognosis and survival [12].

Basal markers like CK 5/6 and EGFR expressing tumor positivity exhibited poor prognosis and screening for these basal marker's expression in tumor cells has become significant in determining prognosis as well as therapeutic approaches in the distinct molecular phenotype of breast carcinoma [13, 14].

Hence in this study, basal markers expressions were compared as well as correlated with the grades of breast carcinoma for a prognostic and predictive indicator. Statistical analysis was done to find out a significant association between the two parameters.

\section{Materials and Method}

In this study, a total number of 48 confirmed cases of breast carcinoma have been taken, which underwent radical mastectomy. Information regarding clinical history and clinical data along with informed consent were taken. The tissue specimens were processed and fixed in $10 \%$ formalin solution. Paraffin embedded tissue sections were stained with haematoxylin and eosin stain. The tumours were graded according to the modified Bloom and Richardson grading system [15].

Immunohistochemical (IHC) panel of two basal markers CK5/6 and EGFR were performed. Cytokeratin 5/6 was considered as positive if any weak or strong cytoplasmic and /or membranous staining was observed in a definite neoplastic cell [16]. EGFR expression was considered positive as a basal marker if more than $1 \%$ of neoplastic cells expressed membranous staining of any intensity according to DAKO criteria [16]. (Table 2)

Statistical analysis was done by using the chisquare test to compare the correlation of EGFR and CK5/6 expression with the histological grades of breast tumour. The result was considered statistically significant if the $P$ value was $<0.05$, calculated by SPSS software.

Table-2: EGFR Assessment

\begin{tabular}{|c|c|c|}
\hline Score & EGFR assessment & Staining pattern \\
\hline $1+$ & Weak & $\begin{array}{c}\text { Faint and incomplete } \\
\text { membrane positivity }\end{array}$ \\
\hline $2+$ & Moderate & $\begin{array}{c}\text { Moderate and complete/ } \\
\text { incomplete membrane positivity }\end{array}$ \\
\hline $3+$ & Strong & $\begin{array}{l}\text { Strong and complete } \\
\text { membrane positivity }\end{array}$ \\
\hline
\end{tabular}

\section{RESULTS}

A total of 48 breast carcinoma cases were obtained. These confirmed cases were further subjected for immunohistochemical analysis of two basal markers. A significant correlation was seen between the histological grades of breast carcinoma and expressions of CK5/6, EGFR basal markers.
In this study, out of 48 breast carcinoma cases, MBR grade II had maximum number of cases (23/48, $47.9 \%)$, followed by MBR grade-III (18/48, 37.5\%) and MBR grade-I $(07 / 48,14.6 \%)$ [Fig.1]. we found a significant association between basal marker expressions of CK5/6, EGFR and histological MBR grades of breast carcinoma $(P=0.032661)$ [Table 3]. MBR grade III showed highest basal marker expression $(15 / 18,83.3 \%)$ [Fig.2]. 
Table-3: Showing distribution of cases according to histological grades and expression of basal markers

\begin{tabular}{|c|c|c|c|c|c|c|c|c|c|c|}
\hline \multirow{2}{*}{$\begin{array}{l}\text { Histological } \\
\text { Grade }\end{array}$} & \multirow{2}{*}{$\begin{array}{l}\mathrm{N} \\
(\%)\end{array}$} & \multicolumn{3}{|c|}{ CK5/6 } & \multicolumn{3}{|c|}{ EGFR } & \multicolumn{3}{|c|}{$\begin{array}{c}\text { Basal Markers } \\
\text { (CK5/6 and/or EGFR) }\end{array}$} \\
\hline & & + & - & $\mathrm{P}$ value & + & - & $\mathrm{P}$ value & + & - & $\mathrm{P}$ value \\
\hline Grade- I & $7(14.6)$ & $2(28.5)$ & $5(71.4)$ & \multirow{3}{*}{0.329} & $1(14.2)$ & $6(85.7)$ & \multirow{3}{*}{0.066} & $2(28.5)$ & $5(71.4)$ & \multirow{3}{*}{0.032661} \\
\hline Grade- II & $23(47.9)$ & $11(47.8)$ & $12(52.2)$ & & $8(34.8)$ & $15(65.2)$ & & $15(65.2)$ & $8(34.8)$ & \\
\hline Grade- III & $18(37.5)$ & $11(61.1)$ & $7(38.9)$ & & $11(61.1)$ & $7(38.9)$ & & $15(83.3)$ & $3(16.7)$ & \\
\hline
\end{tabular}

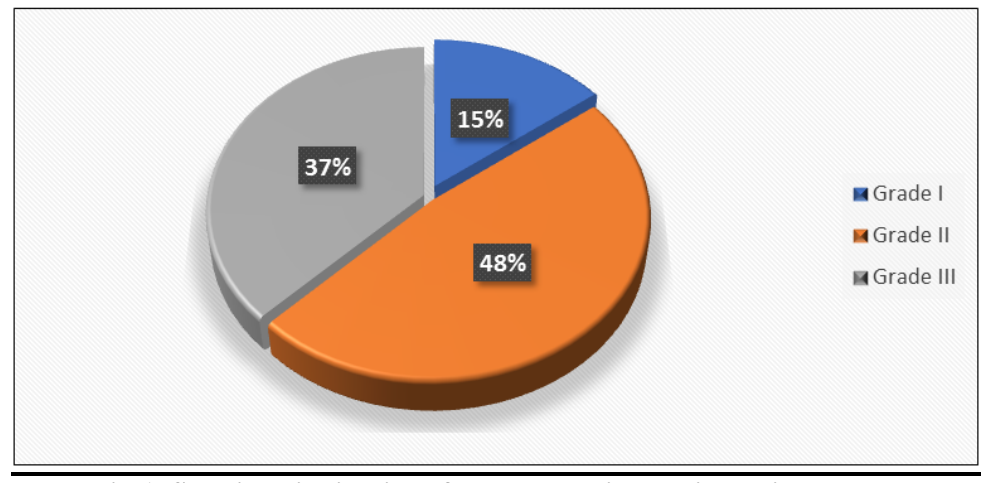

Fig-1: Showing distribution of cases according to histological grades

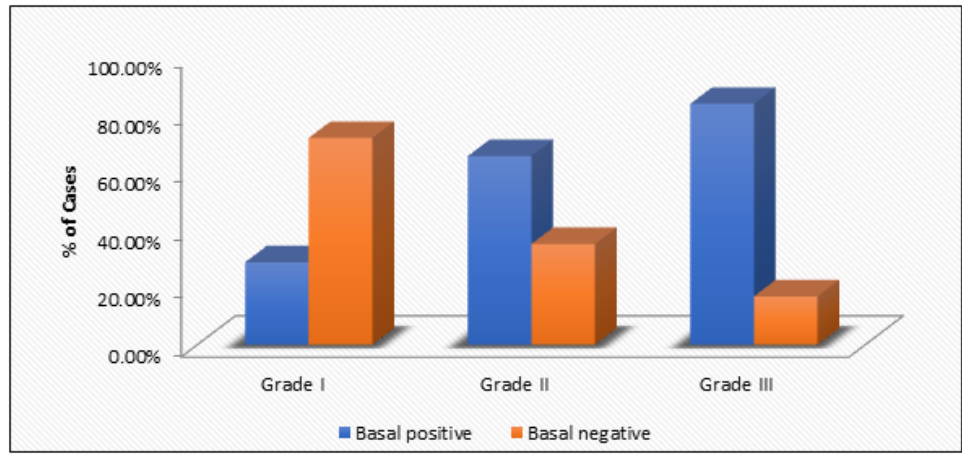

Fig-2: Showing distribution of cases according to histological grade and basal marker expression

\section{DISCUSSION}

Breast carcinoma has shown its heterogenicity and has become one of the leading malignancies worldwide and has been characterized into clinically, morphologically and biologically distinct subgroups $[17,18]$. In normal breast tissue, term basal has been applied to the well-defined myoepithelial cells and basal Cytokeratin (CK) expressing cells that may be found in either a luminal or basal location [13, 27]. EGFR is a $170-\mathrm{kDa}$ membrane-bound tyrosine kinase and has an important role in cell proliferation, migration, and protection against apoptosis mediated by activation of intracellular pathways [19]. The poorer prognosis of breast carcinomas expressing EGFR is likely connected to these functions. Based on gene expression and immunohistochemistry profiling, various IHC markers have been advocated to these subgroups. Among these IHC markers, CK 5/6 and EGFR are basal markers. CK 5/6 and EGFR basal markers have shown positivity in basal-like subtype [20-22]. CK5/6 and EGFR are specific basal markers with prognostic implications. CK $5 / 6$ expression in breast carcinoma implies a 'basal like' molecular phenotype and is associated with poor prognosis [23].
In the present study, the majority of tumors having basal marker expression were poorly differentiated high-grade tumors, which were consistent with the findings of other studies and are associated with poor clinical outcomes $[17,28]$. Studies have shown mitotically active high-grade invasive tumors associated with basal-like breast cancer in young patients expressing CK 5/6 and EGFR positivity [2426]. In this study, the majority of cases had grade II breast carcinoma $(23 / 48,47.9 \%)$ but correlation of CK $5 / 6$ and EGFR basal marker expressions were found to be highly significant $(P=0.0326)$ with grade III tumors $(15 / 18,83.3 \%)$, which correlates with the studies done by Rakha et al. and Malzahn et al. further depicting shorter survival with grade III tumors subgroups [13, 29].

This study predicts poor prognosis in the breast carcinoma cases showing basal markers expressions (CK 5/6 and EGFR positivity) significantly associated with high histological grade and poor survival of the patient. 


\section{CONCLUSION}

In conclusion, the attempt to understand the correlation of Basal markers (CK 5/6 and EGFR) expression with histological grading of breast carcinoma showed significant positivity with high grade tumor affecting the therapeutic as well as prognostic profile of the patients.

\section{Disclosure/conflict of interest}

The authors declare no conflict of interest.

\section{REFERENCES}

1. Onitilio AA, Engel JM, Greenlee RT, Mukesh BN. Breast Cancer Subtypes Based on ER/PR and HER2 expression: Comparison of Clinicopathologic Features and Survival. Clin Med Res. Jun 2009;7(1-2):4-13.

2. Rakha EA, Ellis IO. Triple-negative/basal-like Breast Cancer: Review. Pathology. Jan 2009;41(1):40-7.

3. Pintens S, Neven P, Drijkoningen M, Van Belle V, Moerman P, Christiaens MR, Smeets A, Wildiers H, Bempt IV. Triple negative breast cancer: a study from the point of view of basal CK5/6 and HER-1. Journal of clinical pathology. 2009 Jul 1;62(7):6248.

4. Lin C, Chien SY, Chen LS, Kuo SJ, Chang TW, Chen DR. Triple negative Breast Carcinoma is a Prognostic Factor in Taiwanese woman. BMC Cancer. Jun 2009;9:192

5. Kutomi G, Ohmura T, Suzuki Y, Kameshima H, Shima H, Takamaru T, Satomi F, Otokozawa S, Mori M, Hirata K. Clinicopathological characteristics of basal type breast cancer in triplenegative breast cancer. Journal of cancer therapy. 2012 Oct 31;3(05):836-40.

6. Ma Y, Fan M, Dai L, Kang X, Liu Y, Sun Y, Xiong $\mathrm{H}$, Liang Z, Yan W, Chen K: Expression of p63 and CK5/6 in early-stage lung squamous cell carcinoma is not only an early diagnostic indicator but also correlates with a good prognosis. Thoracic Cancer. 2015, 6(3):288-295.

7. Sundstrom BE, Stigbrand TI: Cytokeratins and tissue polypeptide antigen. The International journal of biological markers. 1994, 9(2):102-108.

8. Böcker W, Bier B, Freytag G, Brömmelkamp B, Jarasch ED, Edel G, Dockhorn-Dworniczak B, Schmid KW. An immunohistochemical study of the breast using antibodies to basal and luminal keratins, alpha-smooth muscle actin, vimentin, collagen IV and laminin. Virchows Archiv A. 1992 Jul 1;421(4):315-22.

9. Liu ZB, Wu J, Ping B, Feng LQ, Shen ZZ, Shao ZM: [Expression of CK5/6 and CK17 and its correlation with prognosis of triple-negative breast cancer patients]. Zhonghua zhong liu za zhi [Chinese journal of oncology] 2008, 30(8):610614. 18 .
10. Mohammadizadeh F, Naimi A, Rajabi $P$, Ghasemibasir H, Eftekhari A. Expression of basal and luminal cytokeratins in breast cancer and their correlation with clinicopathological prognostic variables. Indian journal of medical sciences. 2009 Apr 1;63(4).

11. Hynes NE, Lane HA. ERBB receptors and cancer: the complexity of targeted inhibitors. Nat Rev Cancer. 2005, 5:341-354.

12. Nogi H, Kobayashi T, Suzuki M, Tabei I, Kawase K, Toriumi Y, Fukushima H, Uchida K. EGFR as paradoxical predictor of chemosensitivity and outcome among triple-negative breast cancer. Oncology reports. 2009 Feb 1;21(2):413-7.

13. Rakha E, Reis-Filho JS. Basal-like breast carcinoma: from expression profiling to routine practice. Archives of pathology \& laboratory medicine. 2009 Jun;133(6):860-8.

14. Rao C, Shetty J, Prasad KH. Immunohistochemical profile and morphology in triple-negative breast cancers. Journal of clinical and diagnostic research: JCDR. 2013 Jul;7(7):1361.

15. Elston CW, Ellis IO. Pathological prognostic factors in breast cancer. I. The value of histological grade in breast cancer: experience from a large study with long- term follow- up. Histopathology. 1991 Nov;19(5):403-10.

16. Choccalingam C, Rao L, Rao S. Clinicopathological characteristics of triple negative and non-triple negative high grade breast carcinomas with and without basal marker (CK5/6 and EGFR) expression at a rural tertiary hospital in India. Breast cancer (Auckl). 2012;6:21-9

17. Thike AA, Cheok PY, Jara-Lazaro AR, Tan B, Tan P, Tan PH. Triple-negative breast cancer: clinicopathological characteristics and relationship with basal-like breast cancer. Modern pathology. 2010 Jan;23(1):123-33.

18. Rhee J, Han SW, Oh DY, Kim JH, Im SA, Han W, Park IA, Noh DY, Bang YJ, Kim TY: The clinicopathologic characteristics and prognostic significance of triple-negativity in node-negative breast cancer. BMC Cancer. 2008, 8:307.

19. Quintela I, Corte MD, Allende MT, Vazquez J, Rodriguez JC, Bongera M, Lamelas M, Gonzalez LO, Vega A, García-Muñiz JL, Astudillo A. Expression and prognostic value of EGFR in invasive breast cancer. Oncology reports. $2005 \mathrm{Dec}$ 1;14(6):1655-63.

20. Nielsen TO, Hsu FD, Jensen K, Cheang M, Karaca G, Hu Z, HernandezBoussard T, Livasy C, Cowan $\mathrm{D}$, Dressler L, et al: Immunohistochemical and clinical characterization of the basal-like subtype of invasive breast carcinoma. Clin Cancer Res. 2004, 10(16):5367-5374

21. Perou CM, Sørlie T, Eisen MB, Van De Rijn M, Jeffrey SS, Rees CA, Pollack JR, Ross DT, Johnsen $H$, Akslen LA, Fluge $\varnothing$. Molecular portraits of human breast tumours. Nature. 2000 Aug;406(6797):747-52. 
22. Rakha EA, Aleskandarany M, El-Sayed ME, Blamey RW, Elston CW, Ellis IO, Lee AH: The prognostic significance of inflammation and medullary histological type in invasive carcinoma of the breast. Eur J Cancer. 2009, 45(10):17801787.

23. Bhalla A, Manjari M, Kahlon SK, Kumar P, Kalra $\mathrm{N}$; Cytokeratin 5/6 expression in benign and malignant breast lesions. Indian. 2010; 53(4):67680.

24. Sørlie T, Tibshirani R, Parker J, Hastie T, Marron JS, Nobel A, Deng S, Johnsen H, Pesich R, Geisler S, Demeter J. Repeated observation of breast tumor subtypes in independent gene expression data sets. Proceedings of the national academy of sciences. 2003 Jul 8;100(14):8418-23.

25. Cheang MC, Voduc D, Bajdik C, Leung S, McKinney S, Chia SK, Perou CM, and Nielsen TO: Basal-like breast cancer defined by five biomarkers has superior prognostic value than triple-negative phenotype. Clin Cancer Res. 2008, 14(5):13681376.

26. Turner N, Tutt A, Ashworth A: Hallmarks of 'BRCAness' in sporadic cancers. Nat Rev Cancer. 2004, 4(10):814-819.

27. Rakha EA, Putti TC, Abd El- Rehim DM, Paish C, Green AR, Powe DG, Lee AH, Robertson JF, Ellis IO. Morphological and immunophenotypic analysis of breast carcinomas with basal and myoepithelial differentiation. The Journal of Pathology: A Journal of the Pathological Society of Great Britain and Ireland. 2006 Mar;208(4):495-506.

28. Rakha EA, El-Sayed ME, Green AR, Lee AH Robertson JF, Ellis IO. Prognostic markers in Triple negative breast cancer. Cancer. 2007; 109:25-32.

29. Malzahn K, Mitze M, Thoenes M, Moll R. Biological and prognostic significance of stratified epithelial cytokeratins in infiltrating ductal breast carcinomas. Virchows Arch. 1998; 433:119-129. 